\title{
AN APPROACH SIMILARITY TO CUSTOMER BEHAVIOR IN E-METRICS ECOSYSTEM
}

\author{
Marischa Elveny, M K M Nasution, Muhammad Zarlis, E M Zamzami \\ Fakultas Ilmu Komputer dan Teknologi Informasi, Universitas Sumatera Utara \\ Padang Bulan 20155 USU, Medan, Indonesia
}

\begin{abstract}
Merchant is a business entity in cooperation with banks in the provision of payment. To the north Sumatran region has 33 districts of the city and a population of 13,937,797 inhabitants. Each city district has a variety of merchants that built on each corner or side of the road with a data sample of 1,383 users. To search for users based on their behaviours be competitive merchant who takes the similarity of some objects. The similarity involves characterizing each object or expounds tour-tour of the object. How to measure the similarity to characterize each object resulting in the naming and weighting. The way it is made by comparing to what is common and what is different from the object. Results will be achieved in the form of a method of similarity to look for in a merchant's customer behavior that competitive advantage.
\end{abstract}

Keyword: Merchant, Similarity, E-Metric, Customer Behaviour, Ecosystem

\section{Introduction}

Merchant is a business entity in cooperation with banks in the provision of payment. There are 1,383 customers and 448 merchants be competitive scattered in the region of North Sumatra province. Each city district has a variety of merchants that built on each corner or side of the road. Behaviour of customers in diverse merchant resulting complexity of big data. Technology can solve the problem of large amounts of data, which requires a technique that involves resemblance to group data in specific groups [26].

In similarity techniques, extracting information involves the measurement of the distance between the objects that can be used to trace the origin of the information, or it can be used to predict social behaviour. Ssimilarities are looking for similarities between the input source. The similarity is used to look for linkages or linkages between customer behavior on merchant competitive advantage. The similarity of the two objects is measured based on the concept of proximity, which is used to provide limited value. There are many similarities measurement, but it involves a sequence of components of the object requires a special approach. This study aims to reveal something in common, where each object is grouped by distance proximity, similarity and difference [26].

According to previous studies [28]. Measurement of similarity between two objects is done to avoid duplication on objects that are similar. However, characteristics of the object can be measured by a variety of similarities. The existence of similarity gives the meaning of the measurement results. Measurements such as Jaccard coefficient, mutual information, dice coefficient and coefficient overlap are measurements that concept involves the same vector. Thus, the purpose of this paper is to outline the evidence of the existence of a similarity with the range of values (0.10).

Based on the description above, this study was conducted to get a new similarity method used to find linkage or similarity of customer behaviour on merchant competitive advantage.

\section{Research Purpose}

Merchant is the seller of the goods / services that have a business form (physical store) as well as online stores that cooperate with the Bank in the provision of payment receipt via e-money bank. Similarity (similarity) is a measurement to determine the similarity of one object to another object. Similarities involves characterizing each object to perform ontology and taxonomy or describe in detail the features of the object. That process resulted in the naming and weighting of the characteristics of the object so that gives way to measure similarity. The manner determined by placing a comparison with what is common and what is different from the two objects. Each object or entities contained in 
the study (the universe of discourse) has the characteristics that the features and weight. When an object is known behavior, of course, the efficient behavior of the other can be determined by measuring the similarity or proximity of the objects.

There are three objectives discussion conducted in the research methodology. The first is a competitive merchant and customer, this meant is looking at the behavior of customers when transacting at a merchant. After being awarded the weighting, weighting is a technique of decision-making in a process that involves a variety of factors together by assigning weights to each of these factors in order to obtain a value that results in behavioral similarity. Next look for similarities in customer behavior from the weighting is done to get a new algorithm for the similarity.

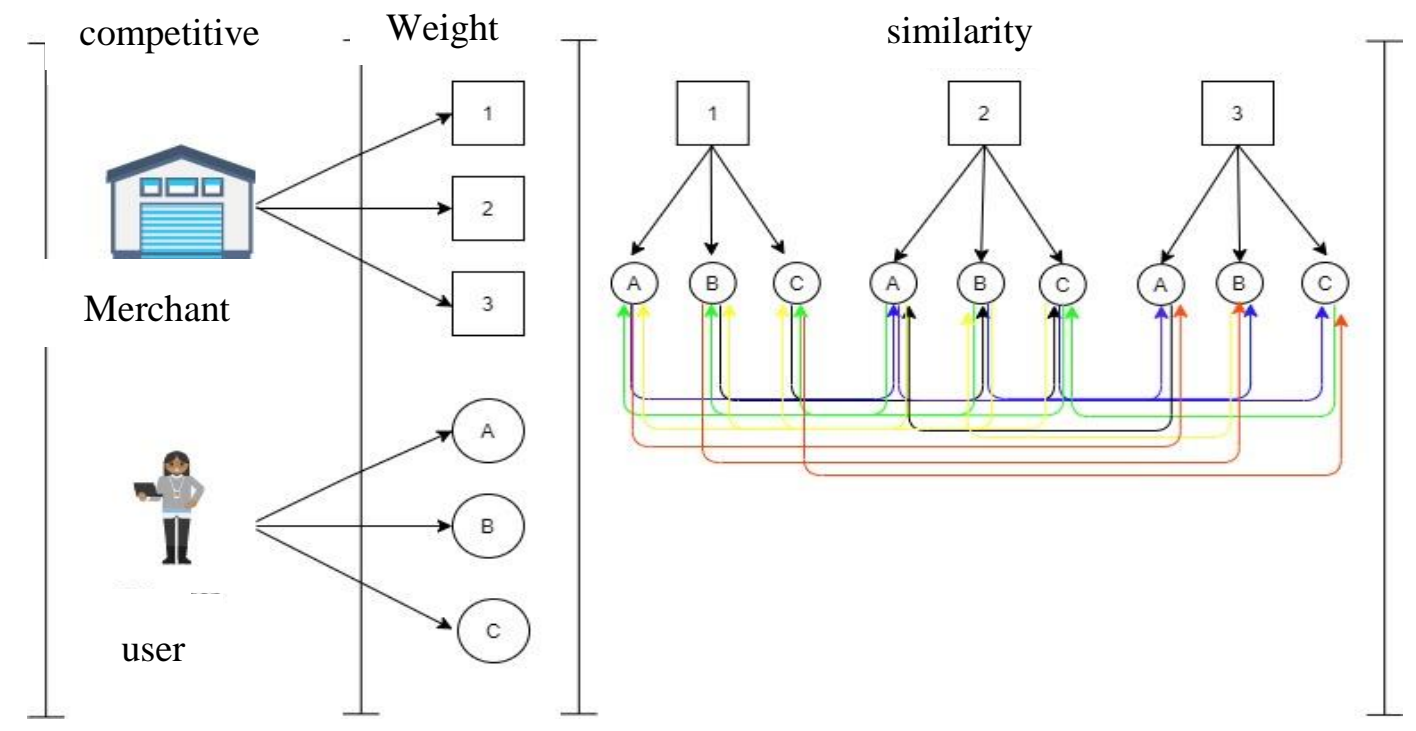

Figure 1. Research methodology

In Figure 1. Try solving our research we made three steps where each round starts from us to become a cluster of traders and users. Then, after being classified, we make a weighting of each relationship and model between the customer and the trader who conducts e-metric transactions. In other words, after determining the weighting, we estimate the relationship and the model and determine the boundary value between. With the insert we determined looking for slices between the customer's research on the tests conducted.

\section{Result and Discussion}

\section{a. Data collection}

This study begins with collecting data and information on the number of subscribers, and the number of merchants that exist in the entire region in northern Sumatra. From the results of the data collected, there are 1383 number of customers spread across North Sumatra with a presentation that can be seen in Table 1 as follows:

\section{Jumlah Merchant}

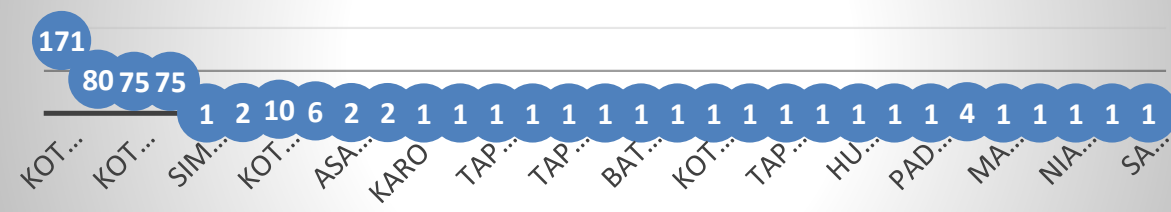

figure 2. Total Merchant in North Sumatra region 
Research will be conducted noticed four stages as in figure 2 .

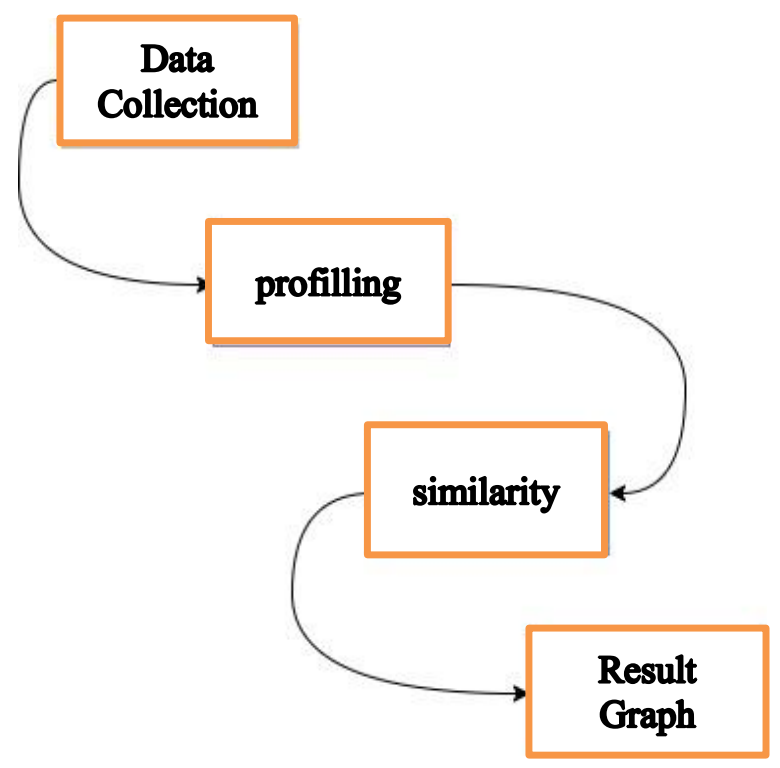

Figure 4. Description Framework Research

Figure 2 shows the steps that will be passed in this study with the following explanation.

From Figure 3.2 it can be seen that there are 448 number of merchants scattered across the North Sumatra and the region has 171 merchant terrain, where the terrain city has among the highest number of other areas.

\section{Data profiling}

From the data grouped, classified and mapped characteristics based on location. To define the vector needed some determinants Name, Latitude (LT), Longitude (LG), District (KC), Regency (KB) and Province (PS).

Table 1. User Data

\begin{tabular}{llllll}
\hline \multicolumn{1}{c}{ Name } & \multicolumn{1}{c}{ LT } & \multicolumn{1}{c}{ LG } & \multicolumn{1}{c}{ KC } & \multicolumn{1}{c}{ KB } & PS \\
\hline tasmin & 3.5723157 & 98.695341 & Medan Area & Field & SU \\
indra zusfika & 3.5773319 & 98.680927 & Medan Maimun & Medan city & SU \\
mridho & 3.5857218 & 98.670415 & terrain Petisah & Medan city & SU \\
suandi tarihoran & 3.56797981 & 98.697066 & Medan Kota & Medan city & SU \\
nurul syamsul rijal & 3.51962833 & 98.788343 & Tanjung Morawa & Deli Serdang & SU \\
irwandi & 2.968872 & 99.628996 & East range & shavings & SU \\
ika septyananing & 3.58907862 & 98.706732 & terrain Tembung & Medan city & SU \\
sendi maulana & 3.59947995 & 98.643895 & Medan Helvetia & Medan city & SU \\
\hline
\end{tabular}

b. similarity

Similarity is a measurement to determine the similarity of one object to another object. Similarities involves characterizing each object to perform ontology and taxonomy or describe in detail the features of the object. 


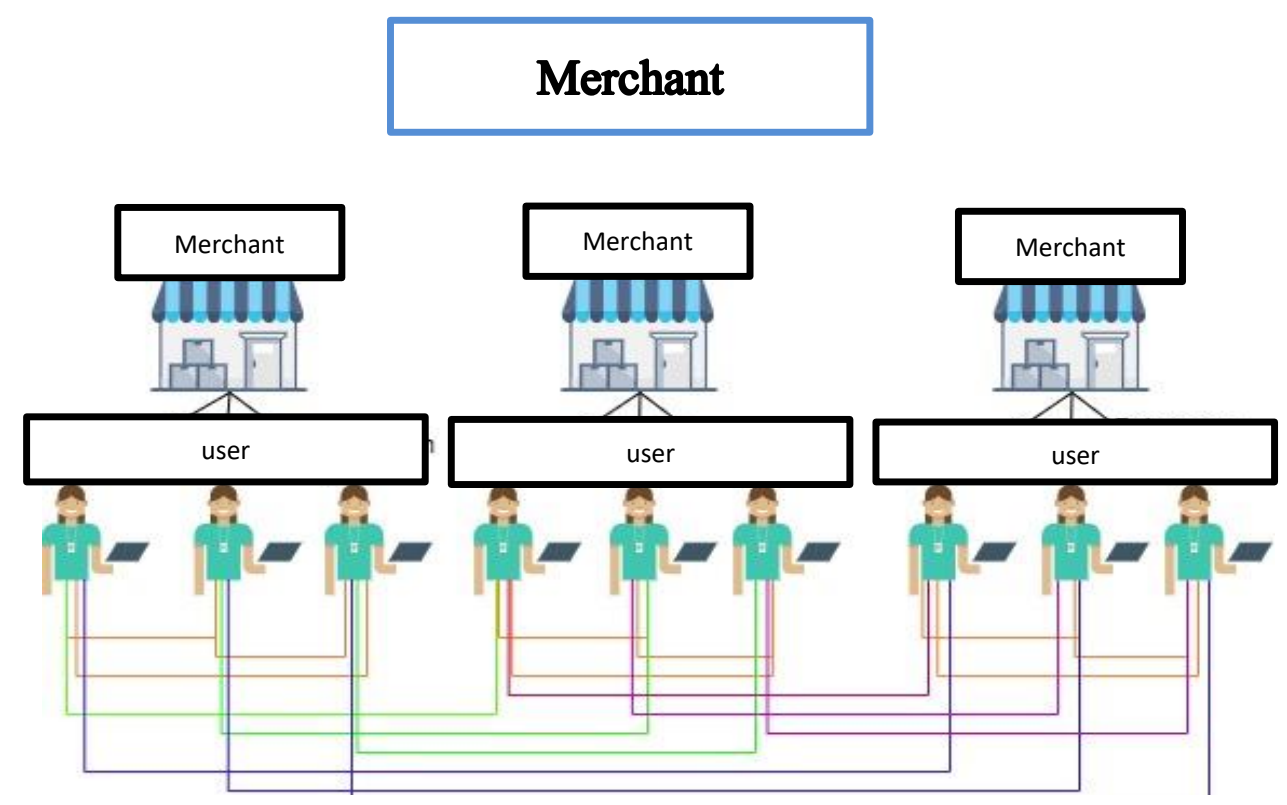

Figure 5. Similarity

The concept of similarity leads to a form of symmetrical like a line or a triangle, namely:

$$
a^{2}=b^{2}+c^{2}
$$

Let $\beta$ (customers) who represent as objects that conduct activities against the merchants, so that each pair of components a, $b \in \beta$, thus the relationship $\beta=(a \rightarrow b)$. As a set, the object $\beta$ consists of the behavior, such that $\mathrm{i}=1, \ldots, \mathrm{n}$. The size of $\beta$ is $|\beta|=\mathrm{n}$, and applies: If the set $\beta=\{\mid \mathrm{i}=1, \ldots, \mathrm{n}\}$ as an object with a behavior of the components of $\beta$, each component has a relationship with the other components. Suppose $|\beta|=\mathrm{N}$, then we obtain $\mathrm{n}(\mathrm{n}-1)$ relationships. Every relationship can be expressed in binary $\{0,1\}$ to affirm the membership of the two components in the $\beta . \beta_{i} \beta_{i} \beta_{i}$ So, every component has one or more relationships with others.

Suppose that $\mathrm{E}$ is a vector, then a couple of, in $\mathrm{E}$ has a resultant vector as follows: $b_{i} b_{j} a_{b}$

$$
a_{b}=b_{i}^{2}+b_{j}^{2}+2 b_{i} E_{j} \cos \alpha
$$

Suppose that for every $a, b \in E$, there is the same application is declared as a $\cap \mathrm{b} \in \mathrm{E}$, with which this application shows the similarity between a and $b$, of course, $a \cap b$ is also a vector which is a vector space E, as well as the weight and direction. The distance to be the difference between a and $\mathrm{b}$ which express $c(a, b)$. As shown in the Definitions 2, which shows the existence of $\mathrm{a}$ and $\mathrm{b}$ in a vector space $\mathrm{E}$, which is expressed in $\mathrm{v}$ or $a \cap b>0$. Similarly, the measurement of the Jaccard coefficient [3], dice coefficient [37], and cosine similarity that conceptually a measure involving the same vector, ie a, b, $a$ $\cap b \neq \in E$ [11]. Based on the implementation can be formulated as follows:

Theorem 1: Jaccard coefficient

There is a vector of the equation $\mathrm{a}, \mathrm{b} \in \mathrm{E}$ and $\mathrm{A} \cap \mathrm{b} \in \mathrm{E}$ where Jaccard coefficient as a measurement of $\mathrm{x}(\mathrm{a}, \mathrm{b})$ then: $j_{c}$

$$
j_{c}=\mathrm{a} \cap \mathrm{b} / \mathrm{a} \cup \mathrm{b}
$$


Where: $a \cup b=a+b-a \cap b$.

Theorem 2: Dice coefficient

There are $\mathrm{a}, \mathrm{b} \in \mathrm{E}$ and $A \cap b \in E$. A measure $\mathrm{x}(\mathrm{a}, \mathrm{b})$ is called dice coefficient if it satisfies

$$
D_{c}=2(\mathrm{a} \cap \mathrm{b}) / \mathrm{a}+\mathrm{b}
$$

As, $=0$ when $a \cap b=0 . j_{c} D_{c}$

Theorem 3: Cosine similarity

There are $a, b \in E$ and $A \cap b \in E$. A measure $x(a, b)$ is the cosine similarity if

$$
C_{s}=\mathrm{x} \cap \mathrm{y} / \sqrt{a b}
$$

As, $=0$ when $a \cap b=0$. For a $=1$, Equation (5) becomes $=x \cap y \cdot j_{c} C_{s} C_{s} \sqrt{a b}$

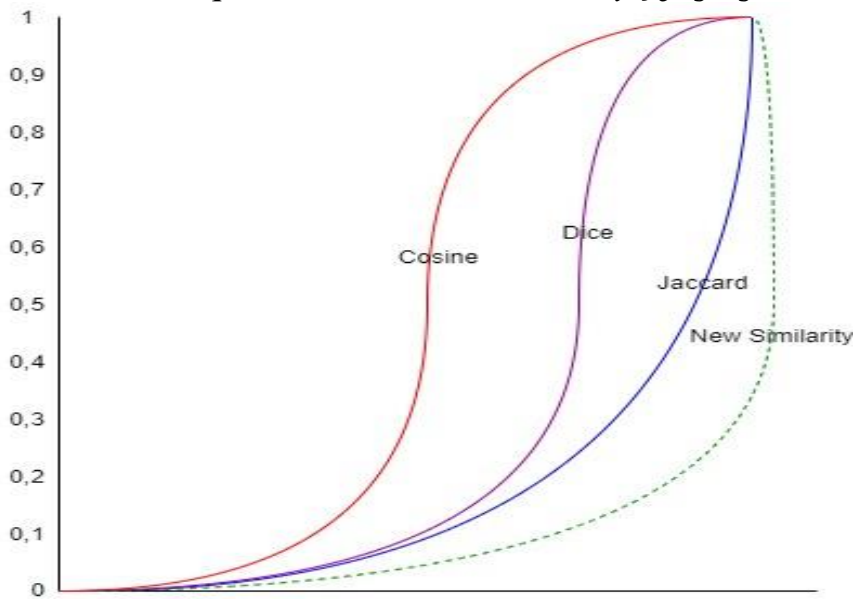

figure 6. Results to be achieved

The results of theorems 1,2 and 3 can be seen in figure 4. This shows that there is a strong symmetrical relationship between vectors in the vector space. In theory, each result of measuring similarity is in a certain position between $\{0,1\}$ and each similarity based on the formula of each method is different from one another. However, the existence of a similarity can still be sought using the derivative formulation that will be carried out in further research, which is seen in the following dotted lines, based on e-metric data to look for the similarity of customer behavior towards a merchant.

\section{Conclusion}

Based on these results a few methods that have been implemented using Jaccard confession looked the blue line, dice coefficient looked at the purple line and the cosine similarity shown in the red line, the research has on semantic web data. The study further studies coloured green with a dotted line that will be applied to the data in the customer e-metrics of mobile payment.

\section{Acknowledgment}

This research was supported by the faculty of computer science and information technology university in North Sumatra. Performed on a doctoral research lab computer science university in North Sumatra.

\section{References}

[1]. Bonchi, F., Castillo, C., Gionis, A. \& Jaimes, A. Social Network Analysis and Mining for Business Applications. ACM Transactions on Intelligent Systems and Technology 2, 1-37 (2012). 
[2]. C. Tat Huei, L. Suet Cheng, L. Chee Seong, A. Aye Khin, R. Ling Leh Bin, Preliminary Study on Consumer Attitude towards FinTech Products and Services in Malaysia. International Journal of Engineering \& Technology. 7, 166 (2018).

[3]. R. Syah, M. K. M. Nasution, E B Nababan, S Efendi (2020). Optimization Tree Base Inference to Customer Behaviour in Mobile Payment. International Conference on Information Technology and Engineering Management ITEM 2020. IOP Material Science and Engineering (MSE).

[4]. Cheng, J. and Zhang, L. (2019), Jaccard coefficient-based bi-clustering and fusion recommender system for solving data sparsity, Lecture Notes in Computer Science (including subseries Lecture Notes in Artificial Intelligence and Lecture Notes in Bioinformatics) 11440 LNAI, 369-380. DOI: 10.1007/978-3-030-16145-3 29.

[5]. Cruz-Benito, J., Therón, R., García-Peñalvo, F. J. \& Pizarro Lucas, E. Discovering usage behaviors and engagement in an Educational Virtual World. Computers in Human Behavior 47, 18-25 (2015).

[6]. Dijkman, Remco M., Marlon Dumas, Boudewijn F. van Dongen, Reina Uba and Jan Mendling. "Similarity of business process models: Metrics and evaluation." Inf. Syst. 36 (2011): 498-516.

[7]. Encyclopedia of Social Network Analysis and Mining (Springer New York, 2018). In the FinTech Book (John Wiley \& Sons, Ltd, 2016), pp. 222-225.

[8]. E. Fernando et al., in Proceedings of 2018 International Conference on Information Management and Technology, ICIMTech 2018(Institute of Electrical and Electronics Engineers Inc., 2018), pp. 114-118.

[9]. E. Ferrara, in Encyclopedia of Social Network Analysis and Mining (Springer New York, 2018), pp. 1297-1300.

[10].F. Amato et al., in Smart Innovation, Systems and Technologies (Springer Science and Business Media Deutschland GmbH, 2019), vol. 98, pp. 53-63.

[11].H. Gimpel, D. Rau, M. Röglinger, Understanding FinTech start-ups - a taxonomy of consumeroriented service offerings. Electronic Markets. 28, 245-264 (2018).

[12].Hussain, M. J., Wasti, S.H., Huang, G., Wei, L., Jiang, Y. and Tang, Y. (2020), An approach for measuring semantic similarity between Wikipedia concepts using multiple inheritances, Information Processing and Management 57(3). DOI: 10.1016/j.ipm.2019.102188.

[13].J.-B. Kim, M.-J. Bae, Location based FDS framework. International Journal of Engineering and Technology (UAE). 7, 72-77 (2018).

[14].J. Freiknecht, S. Papp, J. Freiknecht, S. Papp, in Big Data in der Praxis (Carl Hanser Verlag GmbH \& Co. KG, 2018), pp. 21-186.

[15].J. Lin, C. Dyer, Data-Intensive Text Processing with MapReduce. Synthesis Lectures on Human Language Technologies. 3, 1-177 (2010).

[16].J. Leskovec et al., in Mining of Massive Datasets (Cambridge University Press, 2014), pp. 325383.

[17].Kim, Y. \& Lee, Y. A Study on the Consumers' Perceptions and Behavioral Characteristics toward Fashion Products in Omni-channel Retailing. Journal of the Korean Society of Clothing and Textiles 41, 170-183 (2017).

[18].Kunze, Matthias, Matthias Weidlich and Mathias Weske. "Behavioral Similarity - A Proper Metric." BPM (2011).

[19].M. Steketee, A. Miyaoka, M. Spiegelman, in International Encyclopedia of the Social \& Behavioral Sciences: Second Edition (Elsevier Inc., 2015), pp. 461-467.

[20].M. K. M. Nasution, M. Elveny, R. Syah, S. A. Noah, in Proceedings - 5th International Conference on Electrical Engineering and Informatics: Bridging the Knowledge between Academic, Industry, and Community, ICEEI 2015 (Institute of Electrical and Electronics Engineers Inc., 2015), pp. 496-499.

[21].M. K. M. Nasution, Syah, R. \& Elveny, M. Studies on behaviour of information to extract the meaning behind the behaviour. in Journal of Physics: Conference Series 801, (Institute of Physics Publishing, 2017).

[22].R. Syah, M. K. M. Nasution, E B Nababan, S Efendi. (2019). Optimization Metrics Model: The Mobile Wallet for Merchant Ecosystem. International Conference on Computational Science and Information Management (ICCAI). Journal of Physic: conference series. 
[23].M. K. M. Nasution, O. S. Sitompul, E. P. Sinulingga, S. A. Noah, in Proceedings of 2016 SAI Computing Conference, SAI 2016 (Institute of Electrical and Electronics Engineers Inc., 2016), pp. 1168-1172.

[24].M. K. M. Nasution, O. S. Sitompul, S. Nasution, H. Ambarita, New Similarity, IOP Conf. Series: Materials Science and Engineering 180 (2017) 012297

[25].M. K. M, Nasution, (2020), Comparison of the social network weight measurements, IOP Conference Series: Materials Science and Engineering

[26].M. K. M, Nasution, (2020), Menetukan Keberadaan Suatu Similaritas, ResearcGate, DOI: 10.13140/RG.2.2.27255.16800

[27].M. K. M, Nasution, (2017), Similaritas Berdasarkan Konsep Hubungan, ReseachGate, DOI: 10.13140/RG.2.2.22964.81284

[28].Pandit, R., Sengupta, S., Naskar, S.K., Dash, N.S., \& Sardar, M.M. (2019). Improving Semantic Similarity with Cross-Lingual Resources: A Study in Bangla - A Low Resourced Language. Informatics, 6, 19.

[29].R. Syah, M.K.M Nasution, E. B Nababan, S. Efendi. Knowledge Acceleration Estimator (KAE) Model to Customer Behavior Using Business Metrics. Journal of Theoretical and Applied Information Technology (JATIT 2020).

[30].R. Syah, M. K. M. Nasution, M. Elveny, H. Arbie, M. A. Siregar. Future of Fintech: The Mobile Payment Architecture Model Using Personal Financial Management (PFM). International Conference on Computational Science and Information Management. (IOP Publishing Ltd, Bristol, UK), 49-54 (2019).

[31].R. D. Swetnam et al., Mapping socio-economic scenarios of land cover change: A GIS method to enable ecosystem service modelling. Journal of Environmental Management. 92, 563-574 (2011).

[32].S. T. Asah, A. D. Guerry, D. J. Blahna, J. J. Lawler, Perception, acquisition and use of ecosystem services: Human behavior, and ecosystem management and policy implications. Ecosystem Services. 10, 180-186 (2014).

[33].S. Huang, J. Huang, J. Dai, T. Xie, B. Huang, in Lecture Notes in Business Information Processing (Springer Verlag, 2011), vol. 74 LNBIP, pp. 209

[34].S. Yang, Y. Lu, S. Gupta, Y. Cao, R. Zhang, Mobile payment services adoption across time: An empirical study of the effects of behavioral beliefs, social influences, and personal traits. Computers in Human Behavior. 28, 129-142 (2012).

[35].T. Zhou, An empirical examination of continuance intention of mobile payment services. Decision Support Systems. 54, 1085-1091 (2013).

[36].Stephanie, C. and Sarno, R. (2018), Detecting Business Process Anomaly Using Graph Similarity Based on Dice Coefficient, Vertex Ranking and Spearman Method, Proceedings - 2018 International Seminar on Application for Technology of Information and Communication: Creative Technology for Human Life, semantic 2018 8549830, 171-176. DOI: 10.1109/ISEMANTIC. 2018.8549830.

[37].Sun S-B, Zhang Z-H, et.all, (2017), Integrating Triangle and Jaccard similarities for recommendation, PLoS ONE 12(8): https://doi.org/10.1371/journal.pone 0183570.

[38].Zhang, X., Qin, Z., Liu, X., Hou, Q., Zhang, B., \& Wu, J. (2015). Hadoop-Based Similarity Computation System for Composed Documents.

[39].Zhou, Y., Chen, T., Zhao, Q. and Jiang, T. (2020), Testing the equality of two double-parameter exponential distributions via overlap coefficient, Communications in Statistics - Theory and Methods 49(5), 1248-1260. DOI: 10.1080/03610926.2018.1563169.

[40].Husein, Ismail H Mawengkang, S Suwilo "Modeling the Transmission of Infectious Disease in a Dynamic Network" Journal of Physics: Conference Series 1255 (1), 012052, 2019.

[41].Husein, Ismail, Herman Mawengkang, Saib Suwilo, and Mardiningsih. "Modelling Infectious Disease in Dynamic Networks Considering Vaccine." Systematic Reviews in Pharmacy 11.2, pp. 261-266, 2020.

[42].Husein, Ismail, YD Prasetyo, S Suwilo "Upper generalized exponents of two-colored primitive extremal ministrong digraphs 